\title{
Let Me Whisper in Your Earbud Curating Sound for Ubiquitous Tiny Speakers
}

\author{
MIRIAMA YOUNG
}

In the contemporary moment, the typical sonic experience is solitary and portable-occurring through headphones, mobile phone, tablet, watch, laptop or in the automobile. This article evaluates some of the possibilities and constraints of producing music for Pod-dissemination.

The Sphere is the interior, disclosed, shared realm inhabited by humans.... Spheres are immune-systematically effective space creations for ecstatic beings that are operated upon by the outside.

-PETER SLOTERDIJK [1]

Reflecting the current epoch, Missy Elliott's music video for "Where They From" (2015) opens with a busy urban scene in which a variety of people listen to her song through an array of personal mobile speakers. As the footage cuts, the music is equalized to reflect the visually changing acoustic space: A woman clad with inner earbuds dances and sings along to a tinny, bass-absent rendition. Cut to a manicurist listening through a phone or radio as if through a high-pass filter. Then a man bobs his head from the bubble of his automobile, boomy bass and the remaining frequencies muffled. In a double reflection, we may well experience Elliott's video presentation of ubiquitous portable listening through our own personal media device.

The Elliott video asks the viewer to bear witness to a present-day phenomenon that Michael Bull coined a "largely private and mobile auditory worship" [2]. The iPod's impending technological obsolescence notwithstanding, Bull's observation on ubiquity and privatization is ever more relevant: "iPod culture represents a world in which we all possess mobile phones, iPods or automobiles-it is a culture which universalises the privatisation of public space, and it is a largely auditory privatisation" [3]. This article draws from

Miriama Young (composer, sound artist, scholar), Melbourne Conservatorium of Music, University of Melbourne, Royal Parade, Parkville VIC 3010, Australia. Email: <miriama.young@unimelb.edu.au>.Web: <miriamayoung.com>.

See $<w w w$.mitpressjournals.org/toc/lmj/-/26> for supplemental files associated with this issue. this now-pervasive cultural phenomenon (over 1,385 million smartphones were sold in 2015 alone) [4], in which the portable media device "shape[s] ... sensory experience" [5]. In distinction to the shared experience of high-fidelity loudspeaker arrays for the living room, concert hall or stadium, I classify "Pods" as small speakers designed for a singular and solitary listening experience. Portable Pod listening may engage with the built-in speakers of an automobile, tablet, phone, watch, laptop or headphones including circum-aural and inner earbud, or, as Sumanth Gopinath and Jason Stanyek pointedly put it, "a piece of rubber-sheathed plastic shoved deep in an ear canal" [6]. The possibilities and limitations of Pods for audition are numerous. This article is concerned with soundproduction practices that accommodate and celebrate this listening paradigm.

\section{HISTORICAL BACKGROUND TO TREATMENT OF THE STEREO FIELD}

Stereo sound enabled producers to create the "illusion of space and depth," and mimicked human binaural hearing by "recording two signals from the same sound source" [7]. Stereophonic sound was first introduced into commercial recording in 1954, becoming commonplace by 1958 [8], simultaneous with the commercial release of four-channel tape recorders (or by the late-196os, 8- and 16-track recorders), which made multitracking possible [9].

Multitracking effectively enabled postproduction mixing for the first time. (The multitrack recorder also led to the rise of producers and recording engineers as creative collaborators, a role firmly entrenched-at least in the pop worldtoday [10].) At this time popular music was subject to rather arbitrary and eclectic production practice, not necessarily reflecting the musicians' physical placement in context (for example, vocals and percussion might be sent to one channel and the remaining instruments through the other). Stereo music of the 196os that was produced for home loudspeakers or the automobile engaged in playful panning and fanciful spatial illusion.

Before today's personal listening devices, the speaker's 
mouth, the receiver's ear trumpet, the radio or the telephone were the technological apparatuses available for transmitting messages directly and personally (the old communal "party line" was anything but private) [11]. Through headphones (invented by Ernest Mercadier [1891]; stereo headphones were released by John Koss in 1958), the possibilities for exploiting and intensifying the experience of the auditory panorama were multiplied. The introduction of the Walkman (1979), the portable CD player (1984), the iPod (2001) and now the mobile phone all mimic the traditional telephone model by engaging directly and physically with the ear [12].

These devices, among others, have helped to make the listening experience-with or without headphones-both widely accessible and portable. They also diminish rangeMelissa Pons's test of the iPhone 5 shows that high frequencies (above 16,000 Hz) and especially low ones (below $250 \mathrm{~Hz}$ or approximately $\mathrm{C}_{4}$ ) are significantly unrepresented (below $185 \mathrm{~Hz}$ were nonexistent) [13]. Further, phone speakers collapse the stereophonic mix to a single speaker. Additionally, phone audio is typically coupled with data compression, "psychoacoustically, the $\mathrm{MP}_{3}$ is designed to throw away sonic material that the listener would not hear otherwise," which compromises quality and frequency representation [14]. Leaky earbuds allow external sounds to further color and mask the signal.

\section{HEADPHONE-SPECIFIC MUSIC}

Pod listening has become so commonplace that sound production, performance practice and compositional modalities are now shifting to align with and exploit this medium. Headphones, in particular, present unique possibilities for creative experimentation, and current practice indicates a possible return to the more unconventional and inventive era of stereophonic experimentation. This notion is affirmed by recording engineer Marlan Barry, who observes, "somewhat of a new way of working in the age of ear-buds. . . I know several engineers who have mixed exclusively FOR and ON in-ear monitors." He adds that "this is typically more applicable to the electronic and dance music genres" [15].

The classical music world is, for the most part, not yet anticipating portable mobile device dissemination during the production phase. One exception is Morten Lindberg at $2 \mathrm{~L}$ Recordings in Norway, who apparently tracks classical releases through Sennheiser HD8oo headphones. 2L Recordings intentionally exploit the immersive environment that headphone listening can offer, and the intense clarity and detail of 2 L's recordings is palpable. On-location acoustic reverb simply reinforces the sense of immersion.

Producer and engineer Damon Whittemore states that he still references predominantly to large-to-medium field speakers but, "I have always checked my mixes on headphones; and I certainly try to think about ear candy, those small, subtle sound events that are best heard in headphones (for certain kinds of music)" [16].

Since the Walkman, some commercial music was evidently produced for the headphone era. Some examples spring to mind-in Kate Bush's "Under Ice" (1985), her whisper- singing, breathing and icy acoustic resonances are magnified through high levels of dynamic range compression. Confidential matters are revealed through close listening in De La Soul's whispered "Can You Keep a Secret" (1989); and Björk's intimate narrative in "Cocoon" (2001) is intentionally produced for secretive download and domestic listening "on your laptop" [17].

Uniquely key to composing, vocalizing and producing for headphones is the use of space-and particularly physical proximity. Since the microphone, vocalists in popular genres "invented ... a whole range of new vocal effects and techniques, even new kinds of singing; all based on the simple principle that close microphone placement brings the sound forward" [18]. Quiet singers now croon again, exploiting proximity effect to forge an intimate relationship with the listener. The microphone's capacity to capture and magnify, coupled with the physical closeness of the headphone apparatus, have enabled murmurs, whisper-singing or the featherweight, breathy quality of vocalists like Joanna Newsome, Goldfrapp or Aldous Harding to become magnified and resolute. Similarly, Björk's Vespertine (2001) exploits proximity microphone effects to claim an intimate auditory space between vocalist and listener's imagination. The album "celebrates and rewards headphone-style listening" [19].

\section{THE POD AND PHYSICAL EMBODIMENT}

High in the Caucasus Mountains of the Republic of Georgia, 2007, where medieval life flourishes aided by temperamental electricity generators, I observed suitors at a party engaged in a highly modern form of courtship with their favorite song ("Lady in Red") played back via phone. In an elaborate form of slow dance, he wrapped his arm closely around her neck, whilst his hand pressed the phone to their ears. While they danced, the couple entered a singular, low-fi, mid-frequency, transporting bubble-perhaps Sloterdijk's sphere-through the music.

In this extreme example, sound-source and listener enter a virtual private embodied space: If, in Jonathan Sterne's psychoacoustic notion of hearing, the "the mp3 plays its listener" [20], then likewise the Pod, too, plays its listener by enabling the embodiment of sound in a more intimate and performative way than loudspeakers or live performance. "The [musician's] body, always rootless, now resides in every listener's back pocket" [21]. As the Pod-in its increasingly tiny physical form-becomes synonymous with the listener's body and her motion through space, the listener becomes a surrogate body for the disembodied sound-source, the musician [22].

\section{EXAMPLES OF POD-ART}

Although headphone-specific works are not new, Charles Stankievech observed in $L M J$ as late as 2007 that although the use of headphones was widespread, most sound artists did not produce their work specifically for headphone dissemination: "Rarely does a work require headphones to express its core intentions" [23].

While Pods are generally designed for a single listener (or intimate group of listeners), headphone listening pro- 
vides a solitary and private space that only a single user can inhabit, creating an environment ripe for sonic innovation that reaches beyond mere portability and immersion. It is increasingly common to find sound and music composed and curated, produced and mastered specifically for personal listening environments.

Works designed for headphones are now proliferating. In the following examples, portable listening defines the encounter-from Missy Elliott's video (mentioned above) to Christina Kubisch's Electrical Walks (2004 onward) where purpose-built headphones receive and amplify latent electromagnetic fields in the urban environment-those usually imperceptible, tiny, mysterious signals inherent to the city's ether. Janet Cardiff and George Bures Miller's City of Forking Paths (2014) soundwalk relies on three-dimensional binaural recordings (coupled with video) to augment reality and the listener to a theatrical but plausible environment. Soundscape and narration render Cardiff's whisper in our earbud, "Turn right, but don't fall in" startlingly lifelike, enticing the listener to turn suddenly in the direction of the perceived but imaginary voice. Inverting the private listening space into the public realm, Adam Basanta's 2016 sound installation Curtain (white) is made from 240 hanging pairs of white earbuds awash in white noise.

In my own headphone-specific music, such as "Inner" (2012) and "The Point of Contact" (2008), the listening field is deliberately curated for headphone audition. "The Point of Contact" contrasts verses of close proximity, soft-panned, dry vocals (to match the subject matter) with a chorus of greater frequency range, harmony, stereophonic panorama, near and far field sound placement, compression and reverb depth (intended to create the sensation that the stereophonic space has opened up and perhaps the cranium widened).

While a composer cannot expect high-spec headphone audition, commercial smartphone apps work intrinsically with the phone's (limited) built-in playback. Take for example Eric Whittacre's Deep Field (2015), a work for orchestra, chorus and electronics, where the electronic score is "performed" by members of the audience on their smartphone. In this way the electronic soundscape is distributed spatially (although randomly) throughout the concert hall (peppering this space with a mid-to-high frequency vocal-like but-given the constraints of media player-somewhat distorted oscillating drone). Historically, there are notable examples of creative works that utilize the phone [24], but the epoch of smartphone music may be just beginning.

Hand-built ubiquitous Pods also create new possibilities for spatial distribution of networked sound, such as my SonicPod project for an array of bespoke handmade Pods (each containing microcomputer, microspeaker, Wi-Fi dongle and battery pack), to date used in an installation and concert performance of ChatterBox (Sydney, 2013). Working with prerecorded speech (storytelling) and featuring the distribution of SonicPods randomly through the audience or space, the project celebrates the possibilities as well as the frequency and mp3 compression constraints of the networked tiny speaker medium.

Capitalizing on the Pod's solitary, immersive and transportive power are Björk's virtual-reality music videos-of seascape, internal mouthscape or $3 \mathrm{D}$ body (as exhibited at Carriageworks Sydney, June 2016) coupled with vocals and instrumentals specifically designed for personal headphone/ headset wearing while the listener/viewer is positioned on a swivel chair. Sonically unique to the VR medium, as the listener rotates up to 360 degrees, the spatial placement of the voice remains locked to the singer's physical and visual position on video; essentially the singer's voice rotates in the inverse direction to the listener's head. This renders the listener's experience of the voice convincingly lifelike and richly immersive-as if the performer were physically present in this "performance."

So "Lend Me Your Ears"? For the purposes of this article, another passage from Antony and Cleopatra is more apt: “I'll tell you in your ear" - the passage where Octavia whispers to her brother Caesar [25]. What she relays to her brother, we may only surmise.

\section{References and Notes}

1 Peter Sloterdijk, Bubbles: Spheres I. Frankfurt: Semiotext(e), 2011, p. 28.

2 Michael Bull, Sound Moves: iPod Culture and Urban Experience [Electronic Resource] (Hoboken: Taylor and Francis, 2007) p. 2.

3 Bull [2] p. 4.

4 "Global Smartphone Sales by Operating System from 2009 to 2015," Statista-The Statistics Portal, <www.statista.com/statistics/263445 /global-smartphone-sales-by-operating-system-since-2009/>, accessed 12 June 2016.

5 Sumanth Gopinath and Jason Stanyek, "The Mobilization of Performance," The Oxford Handbook of Mobile Music Studies, Volume 2, July 2014 [Electronic resource].

6 Gopinath and Stanyek [5].

7 Timothy Day, A Century of Recorded Music: Listening to Musical History (London: Yale Univ. Press, 200o) p. 20
8 Day [7].

9 Michael Chanan, Repeated Takes: A Short History of Recording and Its Effects on Music (London: Verso, 1995) p. 144.

10 Chanan [9] pp. 144-145.

11 Miriama Young, Singing the Body Electric: The Human Voice and Sound Technology (Surrey: Ashgate, 2015) p. 157.

12 Young [11].

13 Melissa Pons, "Iphone and IPad Speakers Frequency Response," $<$ https://thesounddesignprocess.wordpress.com/2014/01/o8 /iphone-and-ipad-speakers-frequency-response/\#comment-656>, accessed 12 June 2016.

14 Jonathan Sterne, "The mp3 as Cultural Artifact," in New Media and Society 8(5) (London, Thousand Oaks, CA and New Delhi: SAGE Publications, 2006) p. 835 [DOI: 10.1177/1461444806067737].

15 Marlan Barry, personal correspondence, 13 June 2016. 
16 Damon Whittemore, personal correspondence, 13 June 2016.

17 David Toop, Haunted Weather: Music, Silence and Memory (London: Serpent's Tail, 2004) pp. 226-227.

18 Chanan [9] p. 128.

19 See Young [11] pp. 159-16o.

20 Sterne [14] p. 835.

21 Miriama Young, "Latent Body-Plastic, Malleable, Inscribed: The Human Voice, the Body and the Sound of its Transformation through Technology," Contemporary Music Review Vol. 25, No. 1/2, February/April (2006) pp. 81-92.

22 Young [21].

23 Charles Stankievech, "From Stethoscopes to Headphones: An Acoustic Spatialization of Subjectivity," Leonardo Music Journal Vol. 17 (2007) 57.

24 Cat Hope, "Sound Art/Mobile Art," Sound Scripts: Proceedings of the
Inaugural Totally Huge New Music Festival Conference 2005 Vol. 1 (2006) pp. 42-48.

25 William Shakespeare, "Antony and Cleopatra" in Arden Shakespeare Complete Works, eBook (Bloomsbury, 2014) p. 138.

Manuscript received 1 January 2016.

MIRIAMA YOUNG is a composer, sound artist and writer, on the faculty at The University of Melbourne Conservatorium of Music (VCA \& MCM). Her work explores the human voice and its body through music, sound art and prose. She creates both acoustic and technologically mediated sound and music for the concert hall, and for film, dance, radio and art installations. Her monograph Singing the Body Electric-The Human Voice and Sound Technology was published by Ashgate (Routledge) in 2015.

\section{ANNOUNCING}

\section{Art and Atoms Leonardo eBook}

Edited by Tami I. Spector, Art and Atoms explores the cutting edge of the chemical sciences, art and aesthetics. Tracking chemistry through the 40 years of Leonardo's archives reveals a chronological transformation in the manifestations of "chemistry and art."

In general, the earliest papers, from the 1960s and 1970s, concern themselves with the development of new chemicals and chemically based methods for creating art. Many of the more recent papers have a theoretical slant, with the most recent emphasizing nanoscience. Based on changing trends in the field since the 1960s, the articles in this e-book fall naturally into the following four topic areas:

- Chemical Materiality and Art

- Atomic and Molecular Representations

- Chemical Concepts, Analogy and Metaphor

- Nanoscience

The ebook was produced by Leonardo/ISAST and MIT Press.

See <www.amazon.com/Art-and-Atoms-ebook/dp/B00A9Y3ZCW>. 